\title{
Sistema Poroso e Capacidade de Retenção de Água em Latossolo Submetido a Diferentes Manejos de Plantas INVASORAS EM UMA LAVOURA CAFEEIRA ${ }^{1}$
}

\author{
Pore System and Water Retention Capacity in a Latosol under Different Weed Management \\ Systems in a Coffee Plantation
}

ARAUJO-JUNIOR, C.F. ${ }^{2}$, DIAS JUNIOR, M.S. ${ }^{3}$, GUIMARÃES, P.T.G. ${ }^{4}$ e ALCÂNTARA, E.N. ${ }^{4}$

\begin{abstract}
RESUMO - Os manejos de plantas invasoras em lavouras cafeeiras podem promover alterações estruturais que comprometem a capacidade do solo em infiltrar, distribuir, transmitir e reter água, em função da distribuição dos poros por tamanho. Nesse contexto, o objetivo deste estudo foi verificar a influência da adoção de diferentes manejos de plantas invasoras no sistema poroso e na capacidade de retenção de água em um Latossolo Vermelho distroférrico (LVdf), nas entrelinhas de uma lavoura cafeeira, em relação ao solo sob mata nativa. A área de estudo localiza-se na Fazenda Experimental da Epamig, em São Sebastião do Paraíso, região sul de Minas Gerais. O experimento foi instalado no ano de 1977 em blocos casualizados (DBC), com três repetições. Os seguintes manejos de plantas invasoras foram utilizados nas entrelinhas dos cafeeiros: sem capina (SCAP); capina manual (CAPM); herbicida de pósemergência (HPOS); roçadora (ROÇA); enxada rotativa (ENRT); grade (GRAD); e herbicida de pré-emergência (HPRE). Em dezembro de 2007, amostras de solo com estrutura indeformada foram coletadas aleatoriamente no centro das entrelinhas dos cafeeiros sob os diferentes manejos, nas profundidades de 0-3 cm, 10-13 cm e 25-28 cm, totalizando 315 amostras. Em uma mata nativa (MATA) sob LVdf, adjacente à área de estudo, foram coletadas 15 amostras adicionais por profundidade, as quais serviram de referência para os atributos avaliados. A partir da curva de retenção de água no solo, foi obtida a distribuição de poros por tamanho (macroporosidade: poros com diâmetro $>50 \mu \mathrm{m}$ e microporosidade: poros com diâmetro $<50 \mu \mathrm{m}$ ), e o volume total de poros foi calculado pela equação [VTP = 1-(densidade do solo/ densidade de partículas)]. As principais alterações, tanto na curva de retenção de água como na distribuição de poros por tamanho, ocorreram na profundidade de $0-3 \mathrm{~cm}$. Os extremos foram para o LVdf sob MATA e o solo sob lavoura cafeeira manejado com a GRAD e HPRE. Os demais sistemas de manejo proporcionaram ao LVdf valores intermediários das variáveis avaliadas.
\end{abstract}

Palavras-chave: compactação do solo, estrutura do solo, retenção de água no solo, distribuição de poros por tamanho, métodos de manejo químicos e mecânicos.

\begin{abstract}
The weed management systems applied in coffee plantations can promote changes in soil structure that compromise the capacity of the soil to infiltrate, distribute, transmit and retain water, in function of pore-size distribution. The aim of this study was to verify the effect of applying different techniques of weed management on the pore system and water retention capacity in a Latosol (Oxisol) in the inter-rows of a coffee plantation. The area of study is located at the Epamig Experimental Farm (Latitude 20 $55^{\prime} 00^{\prime \prime}$ S and Longitude 47 $07^{\prime} 10^{\prime \prime}$ 'W) in São Sebastião do Paraíso, southern Minas Gerais. The weed managements evaluated were: without hoe (SCAP), manual hoe
\end{abstract}

1 Recebido para publicação em 19.1.2011 e aprovado em 31.3.2011.

Financiado pelo Consórcio Brasileiro de Pesquisa e Desenvolvimento do Café CBP\&D/Café

2 Engô-Agr ${ }^{\circ}$., MSc., Dr., Pesquisador da Área de Solos, Instituto Agronômico do Paraná - IAPAR, Rodovia Celso Garcia Cid, Km 375, Caixa Postal 48, 86001-970 Londrina-PR, <cezar_araujo@iapar.br>; <cfaj@bol.com.br>; ${ }^{3}$ Engenheiro-Agrícola, Ph.D. in Crop and Soil Science, Professor Associado, Dep. de Ciência do Solo, UFLA, Bolsista do CNPq e da FAPEMIG, <msouzadj@dcs.ufla.br>; ${ }^{4}$ Engo-Agr ${ }^{\circ}$., Dr., Pesquisador do Centro Tecnológico do Sul de Minas, Empresa de Pesquisa Agropecuária de Minas Gerais CTSM/EPAMIG, Campus da UFLA, Caixa Postal 176, 37200-000 Lavras-MG, <paulotgg@epamig.br>; <elifas@epamig.ufla.br>.

Planta Daninha, Viçosa-MG, v. 29, n. 3, p. 499-513, 2011 
(CAPM), post-emergence herbicide (HPOS); mower (ROÇA), rotary tiller (ENRT), coffee tandem disk harrow (GRAD) and pre-emergence herbicide (HPRE). Undisturbed soil samples were collected randomly in the inter-rows of the coffee plants under different weed managements at 0-3, 10-13 and 25-28 cm depths, totaling 315 samples. In a native forest (MATA) adjacent to the LVdf in the study area, 15 additional samples were collected per depth, as reference for the attributes. Soil water retention curve, pore size distribution (macroporosity: pores with effective diameter greater than $50 \mathrm{~mm}$ and microporosity: pores with effective diameter smaller than $50 \mathrm{~mm}$ ) and volumetric total porosity (VTP) were also assessed. The main alteration in soil structure was observed in soil water retention curve and pore size distribution at $0-3 \mathrm{~cm}$ depth. The extreme behaviors for all the physical-hydric attributes assessed were for the LVdf under MATA and the soil under coffee with GRAD and HPRE. The other management systems presented intermediate behavior for all the attributes. The use of the soil with coffee plants decreases volumetric total porosity and macroporosity at $0-3$ and 10-13 cm depths, compared to native forest. There was no effect of the different weed management systems on volumetric total porosity, macro-porosity and micro-porosity at $25-28 \mathrm{~cm}$ depth of LVdf in relation to the soil under native forest.

Keywords: soil compaction, soil structure, soil water retention curve, pore distribution per size; mechanical and chemical management methods.

\section{INTRODUÇÃO}

Os diferentes manejos de plantas invasoras em lavouras cafeeiras podem promover alterações estruturais no solo que influenciam diversamente a germinação, a densidade e a diversidade de plantas invasoras, bem como os atributos físico-hídricos do solo. A ausência de vegetação nas entrelinhas dos cafeeiros proporciona o impacto direto das gotas de chuva, formação do encrostamento superficial e degradação estrutural (Alcântara \& Ferreira, 2000b; Araujo Junior et al., 2008), dificultando com isso a infiltração de água no perfil do solo (Faria et al., 1998). Além disso, alterações estruturais podem comprometer a qualidade física e afetar a produtividade das culturas, pois determinam a profundidade que as raízes podem explorar, a quantidade de água que pode ser armazenada no solo e o movimento de água, ar e da fauna do solo em função da modificação da distribuição dos poros por tamanho (Pagliai et al., 1998; Faria et al., 1998; Pires et al., 2008).

A manutenção das plantas invasoras nas entrelinhas dos cafeeiros pode reduzir os impactos causados pela erosão e compactação do solo, alterando a dinâmica da matéria orgânica, e preservar a estrutura do solo, favorecendo os processos de troca entre a superficie e o subsolo. O manejo de plantas invasoras em lavouras cafeeiras tem sido apontado por diversos autores como um dos principais componentes do manejo que comprometem a qualidade físico-hídrica do solo (Alcântara \& Ferreira, 2000b; Carvalho et al., 2007; Araujo Junior et al., 2008, 2011).

Nesse sentido, o manejo de plantas invasoras não pode ser visto simplesmente a partir de observações pontuais de um processo de competição por água e luz entre as plantas invasoras e a cultura (Faria et al., 1998), uma vez que os manejos adotados para controle dessas plantas podem alterar severamente os atributos fisico-hídricos do solo, dentre os quais se destacam a quantidade de água infiltrada e redistribuída no solo (Faria et al., 1998), a perda de água e arraste de sedimentos (Carvalho et al., 2007), o comportamento compressivo, a suscetibilidade à compactação, a resistência mecânica (Araujo Junior et al., 2008, 2011), a estabilidade dos agregados em água (Alcântara $\&$ Ferreira, 2000b), entre outros. Assim, torna-se essencial o entendimento de como os diferentes manejos de plantas invasoras em lavouras cafeeiras alteram a estrutura do solo.

O manejo inadequado do solo reduz principalmente o volume de macroporos (poros com diâmetro $>50 \mu \mathrm{m}$ ), ao passo que os microporos tendem a aumentar ou permanecer inalterados. Essa redução nos macroporos altera a condutividade hidráulica do solo saturado, a qual é muito sensivel às alterações estruturais (van den Akker \& Soane, 2005). Por outro lado, o aumento do volume de macroporos tem sido relacionado à melhoria da atividade e do crescimento radicular das culturas, mas pode ser prejudicado quando a sua 
continuidade for reduzida e eles forem preenchidos por água (Gliñsky \& Lipiec, 1990). Solos ligeiramente compactados podem ter alta atividade radicular, visto que as raízes podem utilizar os macroporos ainda existentes no interior do agregado para o crescimento e desenvolvimento (Gliñsky \& Lipiec, 1990; van den Akker \& Soane, 2005). Em geral, considera-se que o volume de macroporos de $0,25 \mathrm{~cm}^{3} \mathrm{~cm}^{-3}$ representa boa aeração; entre 0,10 e $0,25 \mathrm{~cm}^{3} \mathrm{~cm}^{-3}$, uma limitada troca gasosa; e abaixo de $0,10 \mathrm{~cm}^{3} \mathrm{~cm}^{-3}$, aeração deficiente (Grable, 1971 citado por Stepniewski et al., 1994) ou solo compactado (Pagliai et al., 2004).

Os efeitos da competição entre as plantas invasoras e os cafeeiros podem ser estudados por meio do grau de interferência, que depende das espécies e da densidade da planta daninha (Ronchi \& Silva, 2006). Esses autores observaram que as espécies de plantas invasoras Bidens pilosa, Commelina diffusa e Richardia brasiliensis afetaram o crescimento de cafeeiros recém-implantados, reduzindo o diâmetro do caule, a altura das plantas, o número de folhas e a massa seca de raiz. Dessas espécies, Bidens pilosa foi a que causou a redução constante das características dos cafeeiros com o aumento da densidade, pelo seu alto potencial competitivo, decorrente de sua alta capacidade de absorção de nutrientes (Ronchi \& Silva, 2006).

Embora dados estejam disponíveis a respeito do manejo de plantas invasoras em lavouras cafeeiras, os efeitos dos manejos em atributos físico-hídricos do solo e na retenção de água têm sido negligenciados. Diante disso, o objetivo deste estudo foi avaliar a influência de diferentes manejos de plantas invasoras em lavoura cafeeira nos atributos físicohídricos e na capacidade de retenção de água em um Latossolo, quando comparado com solo sob mata nativa.

\section{MATERIAL E MÉTODOS}

\section{Localização e caracterização da área experimental}

Este estudo foi realizado na Fazenda Experimental da Empresa de Pesquisa Agropecuária do Estado de Minas Gerais (EPAMIG), localizada no município de São Sebastião do Paraíso, na mesorregião Sul e Sudoeste de Minas Gerais, a uma latitude de $20^{\circ} 55^{\prime} 00^{\prime \prime} \mathrm{S}$ e longitude de $47^{\circ} 07^{\prime} 10^{\prime \prime} \mathrm{W}$ de Greenwich e uma altitude de $885 \mathrm{~m}$. O relevo na área experimental foi classificado como suave ondulado ( $8 \%$ de declividade). A região apresenta precipitação média anual de $1.470,4 \mathrm{~mm}$, temperatura média anual de $20,8{ }^{\circ} \mathrm{C}$, média máxima de $27,6{ }^{\circ} \mathrm{C}$ e média mínima de $14,1^{\circ} \mathrm{C}$.

O experimento foi instalado em setembro do ano 1977, sob um Latossolo Vermelho distroférrico típico (LVdf) (Embrapa, 2006) originado de basalto, de textura argilosa e gibbsítico (Tabela 1). Os teores de $\mathrm{SiO}_{2}, \mathrm{Al}_{2} \mathrm{O}_{3}, \mathrm{Fe}_{2} \mathrm{O}_{3}, \mathrm{TiO}_{2}$ e $\mathrm{P}_{2} \mathrm{O}_{5}$ foram determinados após digestão com $\mathrm{H}_{2} \mathrm{SO}_{4}(9,4 \mathrm{M})$ (Embrapa, 1997). Os valores de $\mathrm{Ki}$ e $\mathrm{Kr}$ foram calculados pelas relações moleculares propostas por Resende \& Santana (1988).

A análise granulométrica foi realizada pelo método da pipeta (Day, 1965), utilizando como dispersante químico $50 \mathrm{~mL}$ de $\mathrm{NaOH}$ a 0,1 mol $_{c} \mathrm{~L}^{-1}$, em contato com a amostra durante 24 horas. A dispersão mecânica foi realizada com a adição de $20 \mathrm{~g}$ de areia grossa e agitação lenta durante quatro horas, em agitador do tipo Wiegner, com velocidade de 30 rotações por minuto (Grohmann \& Raij, 1977).

A área experimental foi plantada com cafeeiros do cultivar Catuaí Vermelho LCH 20772-5-99, no espaçamento de $4 \times 1 \mathrm{~m}$. no ano de

Tabela 1 - Teores de óxidos totais extraídos pelo ataque sulfúrico e granulometria do Latossolo Vermelho distroférrico (LVdf) localizado na Epamig, São Sebastião do Paraíso, Minas Gerais

\begin{tabular}{|c|c|c|c|c|c|c|c|c|}
\hline \multirow{3}{*}{ Uso } & \multicolumn{3}{|c|}{ Óxido } & \multirow{2}{*}{\multicolumn{2}{|c|}{$\begin{array}{c}\text { Índices de } \\
\text { intemperismo }\end{array}$}} & \multicolumn{3}{|c|}{ Granulometria } \\
\hline & $\mathrm{SiO}_{2}$ & $\mathrm{Al}_{2} \mathrm{O}_{3}$ & $\mathrm{Fe}_{2} \mathrm{O}_{3}$ & & & Argila & Silte & Areia \\
\hline & \multicolumn{3}{|c|}{$\left(\mathrm{g} \mathrm{kg}^{-1}\right)$} & $\mathrm{Ki}$ & $\mathrm{Kr}$ & \multicolumn{3}{|c|}{$\left(\mathrm{g} \mathrm{kg}^{-1}\right)$} \\
\hline Mata nativa & 78 & 250 & 260 & 0,53 & 0,32 & 600 & 200 & 200 \\
\hline Cafeeiros & 70 & 250 & 270 & 0,47 & 0,28 & 560 & 230 & 210 \\
\hline
\end{tabular}


1974. Em 26 de dezembro de 2005, devido ao declínio de produção da lavoura implantada no ano de 1974, esta foi substituída por uma lavoura do cultivar Paraíso, variedade MG H419-1, no espaçamento de 4,0 x 0,7 m, sendo a lavoura anterior retirada da área com o auxílio de um subsolador; posteriormente, fez-se o sulcamento, no mesmo local da linha de plantio anterior. Essas operações foram realizadas deixando-se intacto o efeito dos tratamentos ao longo dos anos nas entrelinhas (Araujo Junior et al., 2011).

\section{Delineamento experimental e manejos adotados}

O delineamento experimental utilizado foi o de blocos casualizados, com sete tratamentos e três repetições. Cada condição de manejo foi aplicada em três entrelinhas de $36 \mathrm{~m}$ de comprimento por 2,4 m de largura. As linhas de plantio foram mantidas sempre limpas, por meio de capina manual ou da aplicação de herbicidas.

A correção e adubações organominerais de plantio no ano de 2006 foram realizadas adicionando-se $200 \mathrm{~g} \mathrm{~m}^{-1}$ linear de calcário dolomítico, $200 \mathrm{~g} \mathrm{~m}^{-1}$ linear de gesso agrícola, $5 \mathrm{~L} \mathrm{~m}^{-1}$ linear de palha de café e $400 \mathrm{~g} \mathrm{~m}^{-1}$ de superfosfato simples.

As operações de controle de plantas invasoras foram efetuadas quando $90 \%$ da área se encontrava coberta pelas plantas invasoras e estas apresentavam cerca de $45 \mathrm{~cm}$ de altura (Alcântara \& Ferreira, 2000a, b). Assim, o número médio de operações necessárias para o controle satisfatório das plantas invasoras durante o ano variou de acordo com o método adotado, a seguir relacionado.

a) Sem capina (SCAP): as plantas invasoras foram deixadas em livre crescimento nas entrelinhas dos cafeeiros. As espécies de plantas invasoras encontradas por área na ocasião da amostragem foram: Marmodica charantia, Euphorbia heterophylla, Digitaria insularis, Amaranthus viridis, Panicum maximum, Nicandra physaloides e Ipomoea acuminata.

b) Capina manual (CMAN): realizada com o auxílio de enxada, quando as plantas invasoras atingiam a altura de $45 \mathrm{~cm}$. Foram realizadas oito operações no período de janeiro de 2006 a dezembro de 2007. As espécies foram: Euphorbia heterophylla, Digitaria horizontalis e Cenchrus echinatus.

c) Herbicida de pós-emergência (HPOS): glyphosate foi aplicado com o auxílio de um pulverizador costal, na dose de $2,0 \mathrm{~L} \mathrm{ha}^{-1}$ de produto comercial e $0,72 \mathrm{~kg} \mathrm{ha}^{-1}$ de ingrediente ativo, na formulação de concentrado solúvel, $360 \mathrm{~g} \mathrm{~L}^{-1}$, e aplicado com volume de calda de $400 \mathrm{~L} \mathrm{ha}^{-1}$; foram realizadas oito aplicações no período de janeiro de 2006 a dezembro de 2007. As espécies encontradas nas parcelas sob este manejo foram Amaranthus viridis e Commelina benghalensis.

d) Roçadora (ROÇA): o equipamento utilizado foi uma roçadora da marca Kamaq ${ }^{\circledR}$ modelo KD 132, com largura de corte de 1,32 m e massa estática de $340 \mathrm{~kg}$. Foram realizadas nove operações no período de janeiro de 2006 a dezembro de 2007. As espécies encontradas nas parcelas por ocasião da amostragem foram: Cyperus rotundus, Cynodon dactylon, Amaranthus viridis e Brachiaria decumbens.

e) Enxada rotativa (ENRT): o eixo da enxada rotativa tem cinco flanges, sendo as duas laterais com três facas e as três centrais, com seis facas cada uma. Sua profundidade de trabalho foi de aproximadamente $10 \mathrm{~cm}$. Foram realizadas oito operações no período de janeiro de 2006 a dezembro de 2007. As espécies encontradas nas parcelas sob este manejo foram: Cyperus rotundus, Cynodon dactylon e Bidens pilosa.

f) Grade (GRAD): o equipamento é composto de duas seções dispostas em tandem; cada seção é equipada com sete discos lisos, com largura de corte de 1,3 m e massa estática de $300 \mathrm{~kg}$. Sua profundidade de trabalho foi de aproximadamente $7 \mathrm{~cm}$. Foram realizadas oito operações no período de janeiro de 2006 a dezembro de 2007. As espécies encontradas nas parcelas sob este manejo foram: Cyperus rotundus, Cynodon dactylon e Brachiaria plantaginea.

g) Herbicida de pré-emergência (HPRE): ingrediente ativo oxyfluorfen (2-cloro-a,a,atrifluoro-p-tolyl-3-ethoxy-4-nitrophenyl ether), na dose de $2,0 \mathrm{~kg} \mathrm{ha}^{-1}$ de produto comercial e $0,48 \mathrm{~kg} \mathrm{ha}^{-1} \mathrm{de}$ ingrediente ativo na formulação de concentrado emulsionáve1, $240 \mathrm{~g} \mathrm{~L}^{-1}$ (Rodrigues \& Almeida, 2005), aplicado a um 
volume de calda de $400 \mathrm{~L} \mathrm{ha}^{-1}$. Foram realizadas seis aplicações no período de janeiro de 2006 a dezembro de 2007. Para essa aplicação, cuidou-se para que o solo estivesse livre de restos culturais e plantas invasoras.

Todos os equipamentos utilizados no manejo da lavoura cafeeira no período de janeiro de 2006 a dezembro de 2007 foram tracionados por um trator cafeeiro com potência nominal no motor de $61 \mathrm{cv}$, com massa estática média do trator mais implemento de $3.900 \mathrm{~kg}$, peso de $38.245 \mathrm{~N}$, obtido pela expressão $\left(3.900 \mathrm{~kg} \mathrm{x} \mathrm{9,80665} \mathrm{m} \mathrm{s}^{-2}\right)$, pneus traseiros $12.4-\mathrm{R} 28(31,5 \mathrm{~cm}$ de largura por $71 \mathrm{~cm}$ de diâmetro na pressão de inflação de $18 \mathrm{psi}=124 \mathrm{kPa}$ ) e pneus dianteiros 6-16 $(15,2 \mathrm{~cm}$ de largura por $41 \mathrm{~cm}$ de diâmetro na pressão de inflação de $25 \mathrm{psi}=172 \mathrm{kPa}$ ) (Araujo Junior et al., 2011).

\section{Amostragem e análises de laboratório}

Amostras de solo com estrutura indeformada e deformada foram coletadas entre 17/ 12/2007 e 23/12/2007. Em cada manejo de plantas invasoras, 15 amostras indeformadas de solo foram coletadas aleatoriamente no centro das entrelinhas dos cafeeiros, nas profundidades de $0-3,10-13$ e $25-28 \mathrm{~cm}$, totalizando 315 amostras ( 15 amostras $\mathrm{x} 3$ profundidades $\times 7$ manejos de plantas invasoras). Além da amostragem realizada na lavoura cafeeira, em uma mata nativa sob LVdf, adjacente à área de estudo, foram coletadas 15 amostras adicionais por profundidade, as quais serviram de referência para os atributos físico-hídricos avaliados.

As amostras indeformadas foram coletadas utilizando um amostrador de Uhland e anéis de alumínio de $2,50 \mathrm{~cm}$ de altura por $6,30 \mathrm{~cm}$ de diâmetro, Em seguida, as amostras foram embaladas em filme plástico (PVC) e parafinadas, para preservação da estrutura e transporte até o laboratório.

No laboratório, as amostras indeformadas foram inicialmente preparadas de modo que o volume delas correspondesse ao volume do anel. Posteriormente, essas três amostras de cada profundidade foram saturadas com água destilada em uma bandeja com água até dois terços da altura correspondente à altura do anel, durante 48 horas. Depois de saturadas, as amostras foram submetidas aos seguintes potenciais matriciais $\left(-\psi_{\mathrm{m}}\right): 2,4$ e $6 \mathrm{kPa}$ em mesa de tensão; e 10, 33, 100, 500 e $1.500 \mathrm{kPa}$ em extratores de Richards (Klute, 1986; Dane \& Hopmans, 2002).

Após atingir o equilíbrio, a massa de solo úmido foi determinada. Posteriormente, as amostras foram conduzidas para a estufa a 105-1 $10^{\circ} \mathrm{C}$ durante 48 horas, para obtenção da massa de solo seco e cálculo da densidade do solo (Blake \& Hartge, 1986; Grossman \& Reinsch, 2002); em seguida, determinou-se o conteúdo de água volumétrico (Topp \& Ferre, 2002).

As curvas de retenção de água no solo obtidas em amostras coletadas em áreas submetidas aos diferentes usos/manejos e profundidades foram ajustadas segundo o modelo de van Genuchten (1980) (equação 1), considerando-se a restrição de Mualen $(\mathrm{m}=$ $1-1 / \mathrm{n})$, por meio do software Soil Water Retention Curve - SWRC (Dourado-Neto et al., 2001).

$$
\theta=\theta_{r}+\frac{\theta s-\theta r}{\left[1+\left(\alpha \cdot \psi_{m}\right)^{n}\right]^{m}}
$$

em que $\alpha, n$ e m são parâmetros de ajuste da equação com suas limitações, sendo $\alpha>1, n>$ 1 e $0<m<1$ (Kutilek et al., 2007); $\theta$, o conteúdo de água estimado; $\theta_{r}$ o conteúdo de água residual ou no ponto de murcha permanente (van Genuchten, 1980; Pires et al., 2008); $\theta_{s,}$ o conteúdo de água na saturação, correspondente ao volume total de poros (VTP); e $\psi_{m}$, o potencial matricial, em -kPa.

O volume total de poros foi determinado utilizando-se a equação 2 (Vomocil, 1965; Flint \& Flint, 2002).

$$
V T P=1-\left(\frac{D s}{D p}\right)
$$

em que $V T P$ é o volume total de poros; $D s$, densidade do solo, em $\mathrm{g} \mathrm{cm}^{-3}$; e $D p$, a densidade de partículas, em $\mathrm{g} \mathrm{cm}^{-3}$. A densidade de partículas foi determinada pelo método do picnômetro (Blake \& Hartge, 1986b). Três repetições de cada profundidade dentro de cada 
manejo foram utilizadas para obter as curvas de retenção de água, as quais foram utilizadas para gerar modelos de ajuste considerando toda a profundidade estudada $(0-28 \mathrm{~cm})$ para a posição de amostragem centro da entrelinha dos cafeeiros.

A altura de ascensão da água (h), descrita pela equação de Jurin (equação 3), permite determinar a distribuição de poros por tamanho a partir da curva de retenção de água no solo, usando o conceito de tamanhos equivalentes derivados de um tubo capilar (Horton et al., 1989; Pagliai, 2007). A equação 3 relaciona a altura de ascensão capilar ao raio do poro.

$$
h=\frac{(2 \gamma \cos \theta)}{r \rho g}
$$

em que $h$ é a altura de ascensão capilar expressa em metros; $\gamma$, a tensão superficial da água $\left(72,75 \mathrm{mN} \mathrm{m}^{-1}\right.$ a $\left.20^{\circ} \mathrm{C}\right) ; \theta$, o ângulo de contato entre liquido e sólido, o qual, neste trabalho, foi assumido como sendo zero; $r$, o raio do poro; $g$, a aceleração da gravidade $\left(9,80 \mathrm{~m} \mathrm{~s}^{-2}\right)$; e $\rho$, a densidade da água $\left(0,9982 \mathrm{Mg} \mathrm{m}^{-3}\right.$ a $\left.20^{\circ} \mathrm{C}\right)$.

Os resultados da distribuição de poros por tamanho e da porosidade total do solo foram submetidos à análise de variância; a comparação das médias foi feita pelo teste de ScottKnott, utilizando-se o programa estatístico Sisvar (Ferreira, 2000).

\section{RESULTADOS E DISCUSSÃO}

\section{Curvas de retenção de água no solo}

Os resultados dos parâmetros do ajuste do modelo de van Genuchten (1980) para as curvas de retenção de água, para o LVdf sob MATA e diferentes sistemas de manejo das plantas invasoras, são apresentados na Tabela 2. O modelo ajustou-se adequadamente aos dados observados, com coeficientes de determinação $\left(R^{2}\right)$ entre 0,97 e 0,99, todos significativos a $1 \%$ de probabilidade pelo teste $\mathrm{F}$ (Tabela 2).

Os valores da $\theta$ sat (Tabela 2) variaram de $0,58 \mathrm{~cm}^{3} \mathrm{~cm}^{-3}$ a $0,73 \mathrm{~cm}^{3} \mathrm{~cm}^{-3}$. O valor máximo foi para o LVdf sob MATA na profundidade de
0-3 cm, ao passo que o valor mínimo foi para o solo sob o manejo de plantas invasoras (GRAD e HPRE) na mesma profundidade (Tabela 2), indicando que esses manejos proporcionam redução na porosidade total. A ausência de ação antrópica no solo sob MATA favorece o maior volume total de poros e, consequentemente, proporciona aumento no conteúdo de água na saturação, menor densidade do solo, além de acréscimo nos teores de matéria orgânica do solo sob esse uso. Além disso, ressalta-se que solos gibbsíticos, $\mathrm{Ki} \leq 0,75$ (Resende \& Santana, 1988), como o do presente estudo, exibem valores de densidade do solo próximos a $1,0 \mathrm{Mg} \mathrm{m}^{-3}$, macroporosidade elevada e bem conectada, com valores superiores a $0,18 \mathrm{~cm}^{3} \mathrm{~cm}^{-3}$, como resultado da sua estrutura granular muito pequena e muito bem expressa (Ferreira et al., 1999). Essa estrutura influencia a porosidade total, bem como reduz a resistência mecânica do solo, expressa pela capacidade de suporte de carga, e aumenta a suscetibilidade do solo à compactação (Ajayi et al., 2009).

Todos os sistemas de manejo de plantas invasoras avaliados proporcionaram ao LVdf redução dos valores de $\theta$ sat e porosidade total nas profundidades de $0-3$ e $10-13 \mathrm{~cm}$ (Tabela 2 e Figura 2), quando comparados ao solo sob MATA. Entretanto, a redução da $\theta$ sat e do VTP foi mais acentuada nos manejos GRAD e HPRE, na profundidade de $0-3 \mathrm{~cm}$ (Figura 2), indicando maior degradação da estrutura do solo em relação aos demais sistemas de manejo. As menores densidade e diversidade de plantas invasoras no campo sob os manejos GRAD e HPRE favorecem uma cobertura vegetal limitada e a degradação da estrutura do solo, devido ao impacto direto das gotas de chuva e à exposição a ciclos de umedecimento e secagem, os quais podem transformar a estrutura do solo em uma estrutura maciça e compacta (Pagliai, 2007). Além disso, para o manejo GRAD, como a largura de corte do equipamento foi insuficiente para cobrir toda a entrelinha em uma única passagem, o aumento na intensidade de tráfego e no contato dos pneus e dos equipamentos na superficie do solo pode proporcionar aumento do estado de compactação do solo (Araujo Junior et al., 2011), reduzindo a porosidade total e a $\theta$ sat. Pires et al. (2008) observaram que o aumento do número 
Tabela 2 - Parâmetros da curva de retenção de água no solo obtidos da equação de van Genuchten para o Latossolo sob mata nativa e lavoura cafeeira submetido a diferentes sistemas de manejo de plantas invasoras, na posição de amostragem centro das entrelinhas

\begin{tabular}{|c|c|c|c|c|c|c|c|c|}
\hline \multirow{3}{*}{ Parâmetro } & \multicolumn{4}{|c|}{ Mata nativa (MATA) } & \multicolumn{4}{|c|}{ Sem capina (SCAP) } \\
\hline & \multicolumn{4}{|c|}{ Profundidade $(\mathrm{cm})$} & \multicolumn{4}{|c|}{ Profundidade $(\mathrm{cm})$} \\
\hline & $0-3$ & $10-13$ & $25-28$ & $0-28$ & $0-3$ & $10-13$ & $25-28$ & $0-28$ \\
\hline$\theta$ sat $\left(\mathrm{cm}^{3} \mathrm{~cm}^{-3}\right)$ & 0,73 & 0,67 & 0,64 & 0,67 & 0,66 & 0,61 & 0,59 & 0,63 \\
\hline$\theta \operatorname{res}\left(\mathrm{cm}^{3} \mathrm{~cm}^{-3}\right)$ & 0,21 & 0,23 & 0,26 & 0,23 & 0,24 & 0,27 & 0,25 & 0,27 \\
\hline$\alpha\left(\mathrm{kPa}^{-1}\right)$ & 6,9566 & 4,8428 & 3,2468 & 4,0353 & 1,1346 & 2,0623 & 1,2384 & 1,1185 \\
\hline $\mathrm{n}$ & 1,3575 & 1,3917 & 1,3815 & 1,4214 & 1,7069 & 1,4391 & 1,9311 & 1,7442 \\
\hline $\mathrm{m}$ & 0,2633 & 0,2815 & 0,2762 & 0,2965 & 0,4141 & 0,3051 & 0,4822 & 0,4267 \\
\hline $\mathrm{R}^{2}$ & 0,98 & 0,99 & 0,97 & 0,98 & 0,99 & 0,99 & 0,97 & 0,99 \\
\hline Valor de F & 340,63 & 661,47 & 218,96 & 452,29 & 1718,19 & 981,97 & 190,36 & 727,04 \\
\hline Nível de sig (\%) & $<0,001$ & $<0,001$ & $<0,001$ & $<0,001$ & $<0,001$ & $<0,001$ & $<0,01$ & $<0,001$ \\
\hline \multirow{3}{*}{ Parâmetro } & \multicolumn{4}{|c|}{ Capina manual (CAPM) } & \multicolumn{4}{|c|}{ Herbicida de pós-emergência (HPÓS) } \\
\hline & \multicolumn{4}{|c|}{ Profundidade } & \multicolumn{4}{|c|}{ Profundidade $(\mathrm{cm})$} \\
\hline & $0-3$ & $10-13$ & $25-28$ & $0-28$ & $0-3$ & $10-13$ & $25-28$ & $0-28$ \\
\hline$\theta$ sat $\left(\mathrm{cm}^{3} \mathrm{~cm}^{-3}\right)$ & 0,61 & 0,60 & 0,62 & 0,62 & 0,61 & 0,60 & 0,63 & 0,62 \\
\hline$\theta$ res $\left(\mathrm{cm}^{3} \mathrm{~cm}^{-3}\right)$ & 0,28 & 0,25 & 0,24 & 0,26 & 0,29 & 0,27 & 0,24 & 0,27 \\
\hline$\alpha\left(\mathrm{kPa}^{-1}\right)$ & 1,5662 & 0,9340 & 1,0223 & 1,0838 & 1,8833 & 1,7091 & 1,2936 & 1,6953 \\
\hline $\mathrm{n}$ & 1,3227 & 1,7858 & 1,7430 & 1,5967 & 1,4569 & 1,4856 & 1,7198 & 1,5207 \\
\hline $\mathrm{m}$ & 0,2440 & 0,4400 & 0,4263 & 0,3737 & 0,3136 & 0,3269 & 0,4185 & 0,3424 \\
\hline $\mathrm{R}^{2}$ & 0,99 & 0,99 & 0,99 & 0,99 & 0,99 & 0,99 & 0,99 & 0,99 \\
\hline Valor de F & $1.972,70$ & 938,94 & $1.079,78$ & 883,61 & $3.347,19$ & $4.136,27$ & 922,23 & 6265,52 \\
\hline Nível de sig. (\%) & $<0,001$ & $<0,001$ & $<0,001$ & $<0,001$ & $<0,001$ & $<0,001$ & $<0,001$ & $<0,001$ \\
\hline \multirow{3}{*}{ Parâmetro } & \multicolumn{4}{|c|}{ Roçadora (ROÇA) } & \multicolumn{4}{|c|}{ Enxada rotativa (ENRT) } \\
\hline & \multicolumn{4}{|c|}{ Profundidade $(\mathrm{cm})$} & \multicolumn{4}{|c|}{ Profundidade $(\mathrm{cm})$} \\
\hline & $0-3$ & $10-13$ & $25-28$ & $0-28$ & $0-3$ & $10-13$ & $25-28$ & $0-28$ \\
\hline$\theta$ sat $\left(\mathrm{cm}^{3} \mathrm{~cm}^{-3}\right)$ & 0,61 & 0,61 & 0,62 & 0,60 & 0,64 & 0,61 & 0,63 & 0,63 \\
\hline$\theta \operatorname{res}\left(\mathrm{cm}^{3} \mathrm{~cm}^{-3}\right)$ & 0,31 & 0,27 & 0,25 & 0,28 & 0,29 & 0,26 & 0,23 & 0,26 \\
\hline$\alpha\left(\mathrm{kPa}^{-1}\right)$ & 1,5713 & 2,2970 & 2,5577 & 1,7332 & 0,9195 & 1,9459 & 2,0728 & 1,4705 \\
\hline $\mathrm{n}$ & 1,5735 & 1,5389 & 1,4559 & 1,5674 & 1,7706 & 1,4702 & 1,4828 & 1,5528 \\
\hline $\mathrm{m}$ & 0,3645 & 0,3502 & 0,3131 & 0,3620 & 0,4352 & 0,3198 & 0,3256 & 0,3560 \\
\hline $\mathrm{R}^{2}$ & 0,99 & 0,99 & 0,99 & 0,99 & 0,99 & 0,99 & 0,99 & 0,99 \\
\hline Valor de $\mathrm{F}$ & $1.924,81$ & $4.322,62$ & $2.650,99$ & $1.990,13$ & $3.874,20$ & $3.155,94$ & $3.868,55$ & $6.812,42$ \\
\hline Nível de sig. (\%) & $<0,001$ & $<0,001$ & $<0,001$ & $<0,001$ & $<0,001$ & $<0,001$ & $<0,001$ & $<0,001$ \\
\hline \multirow{3}{*}{ Parâmetro } & \multicolumn{4}{|c|}{ Grade (GRAD) } & \multicolumn{4}{|c|}{ Herbicida de pré-emergência (HPRÉ) } \\
\hline & \multicolumn{4}{|c|}{ Profundidade $(\mathrm{cm})$} & \multicolumn{4}{|c|}{ Profundidade $(\mathrm{cm})$} \\
\hline & $0-3$ & $10-13$ & $25-28$ & $0-28$ & $0-3$ & $10-13$ & $25-28$ & $0-28$ \\
\hline$\theta$ sat $\left(\mathrm{cm}^{3} \mathrm{~cm}^{-3}\right)$ & 0,58 & 0,61 & 0,63 & 0,60 & 0,58 & 0,60 & 0,63 & 0,60 \\
\hline$\theta \operatorname{res}\left(\mathrm{cm}^{3} \mathrm{~cm}^{-3}\right)$ & 0,32 & 0,26 & 0,25 & 0,28 & 0,24 & 0,24 & 0,24 & 0,24 \\
\hline$\theta\left(\mathrm{kPa}^{-1}\right)$ & 1,6966 & 2,4668 & 1,7758 & 1,8484 & 1,4329 & 2,4633 & 1,4825 & 1,5708 \\
\hline $\mathrm{n}$ & 1,5204 & 1,5438 & 1,5299 & 1,5529 & 1,4469 & 1,4700 & 1,5875 & 1,5089 \\
\hline $\mathrm{m}$ & 0,3423 & 0,3522 & 0,3464 & 0,3560 & 0,3089 & 0,3197 & 0,3701 & 0,3373 \\
\hline $\mathrm{R}^{2}$ & 0,99 & 0,99 & 0,99 & 0,99 & 0,99 & 0,99 & 0,99 & 0,99 \\
\hline Valor de $\mathrm{F}$ & 883,97 & $1.598,54$ & $1.1731,19$ & $1.104,04$ & $4.818,56$ & $3.810,49$ & $2.105,45$ & $8.711,18$ \\
\hline Nível de sig. (\%) & $<0,001$ & $<0,001$ & $<0,001$ & $<0,001$ & $<0,001$ & $<0,001$ & $<0,001$ & $<0,001$ \\
\hline
\end{tabular}


de ciclos de umedecimento e secagem promove aumento da porosidade de um solo arenoso não cultivado coberto por pastagem $\mathrm{e}$ plantas invasoras. Por outro lado, esses autores observaram que, em um Nitossolo eutrófico argiloso cultivado com cafeeiros, o aumento do número de ciclos de umedecimento e secagem promove redução na porosidade do solo e, consequentemente, da $\theta$ sat.

Os valores da $\theta$ res (Tabela 2), que corresponde ao volume de poros $<0,2 \mu \mathrm{m}$ (Tabela 3) e ao volume de água retido no potencial matricial $-1.500 \mathrm{kPa}(-\Psi \mathrm{m})$ ou ponto de murcha permanente (PMP), variaram de 0,21 a $0,32 \mathrm{~cm}^{3} \mathrm{~cm}^{-3}$, para o LVdf sob MATA e GRAD, na profundidade de $0-3 \mathrm{~cm}$, respectivamente. $\mathrm{O}$ maior volume de água retido nos menores potenciais $(-1.500 \mathrm{kPa})$ no manejo GRAD pode ser devido à constante ruptura da estrutura, desagregação e, consequentemente, maior aproximação das partículas proporcionada pela grade. Essa maior aproximação das partículas sólidas do solo aumenta os efeitos da matriz deste sobre a água, a partir das forças de adsorção ou tensão superficial na interface ar-água.

Os valores de $\alpha$ variaram de 0,9195 a $6,9566 \mathrm{kPa}^{-1}$ para o LVdf sob o manejo ENRT e MATA, respectivamente, na profundidade de 0-3 cm (Tabela 2), indicando que esse parâmetro da curva de retenção de água foi amplamente alterado pelo uso do solo com cafeeiros e submetido a diferentes manejos de plantas invasoras. A amplitude de valores para o parâmetro $\alpha$ observada no presente estudo foi superior à encontrada por Carducci et al. (2011) $\left(\alpha\right.$ 0,719-2,311 $\left.\mathrm{kPa}^{-1}\right)$ para Latossolos com conteúdo de argila entre 152 e $716 \mathrm{~g} \mathrm{~kg}^{-1}$. Esses autores observaram ainda que o parâmetro $\alpha$ apresentou baixa correlação negativa com o teor de argila.

Os valores de $\mathrm{m}$ variaram de 0,2440 a 0,4822, e os de n, de 1,3227 a 1,9311 (Tabela 2). Destaca-se ainda que os valores mínimos para os parâmetros $\mathrm{n}$ e $\mathrm{m}$ foram encontrados na curva de retenção obtida para o LVdf submetido ao manejo CAPM, na profundidade de 0-3 cm (Tabela 2). Por sua vez, os valores máximos dos parâmetros $\mathrm{m}$ e $\mathrm{n}$ foram obtidos para a curva de retenção do LVdf no manejo SCAP, na profundidade de $25-28 \mathrm{~cm}$ (Tabela 2). $\mathrm{O}$ parâmetro $\mathrm{n}$ está intimamente relacionado à distribuição de poros por tamanho, demonstrando que, com o aumento desse parâmetro, ocorre expansão na escala log e redução no tamanho dos poros (Horton et al., 1987), podendo ser observado decaimento abrupto da retenção de água para potenciais menores que $-2 \mathrm{kPa}$ (Figura 1A).

O uso do solo com cafeeiros e a utilização de diferentes sistemas de manejo de plantas invasoras alteraram as formas das curvas de retenção de água do LVdf (Figura 1A, B e C). Contudo, destaca-se que as principais alterações na forma e nas propriedades da curva de retenção de água foram observadas na profundidade de $0-3 \mathrm{~cm}$ (Figura 1A). Isso provavelmente se deve à variação observada nos atributos físicos (densidade do solo e matéria orgânica) (Araujo Junior et al., 2011), os quais alteram os parâmetros da forma da curva de retenção de água, m e $n$ (Tabela 2) e, consequentemente, a distribuição de poros por tamanho (Tabela 3 e Figura 2A).

O solo sob MATA na profundidade de $0-3 \mathrm{~cm}$ apresentou redução abrupta da retenção de água com a redução do potencial matricial; o LVdf sob este uso apresentou a menor retenção de água entre os potenciais de -2 a $-6 \mathrm{kPa}$ e de $-500 \mathrm{kPa}$ a $-1.500 \mathrm{kPa}$ (Figura 1A). Provavelmente, isso se deve à maior distribuição dos poros nas classes $>145 \mu \mathrm{m}$ e de $145-50 \mu \mathrm{m}$ e menor na classe de poros $<0,2 \mu \mathrm{m}$ (Tabela 2 ) e microporosidade (Figura 2), bem como ao maior volume total de poros (Figura 2). Por outro lado, esse mesmo uso proporcionou maior retenção de água entre os potenciais $4 \mathrm{kPa}$ e $-1.500 \mathrm{kPa}$, na profundidade $25-28 \mathrm{~cm}$ (Figura 1C).

O conteúdo de água do LVdf na profundidade de 0-3 cm entre os $\Psi-2 \mathrm{kPa}$ a $-100 \mathrm{kPa}$ sob o manejo CAPM foi superior quando comparado ao solo sob MATA e sob os demais sistemas de manejo de plantas invasoras (Figura 1A). Isso indica que o manejo CAPM proporciona ao LVdf maior distribuição de poros intermediários na profundidade de $0-3 \mathrm{~cm}$, quando comparado ao solo sob MATA e demais sistemas de manejo de plantas invasoras. Nos potenciais matriciais menores que $-100 \mathrm{kPa}$, o conteúdo de água na profundidade de $0-3 \mathrm{~cm}$ decresce na seguinte ordem: GRAD > CAPM > HPOS $=$ ROÇA $>$ ENRT $>$ HPRE $>$ SCAP > MATA (Figura 1A). Destaca-se ainda que, entre os 

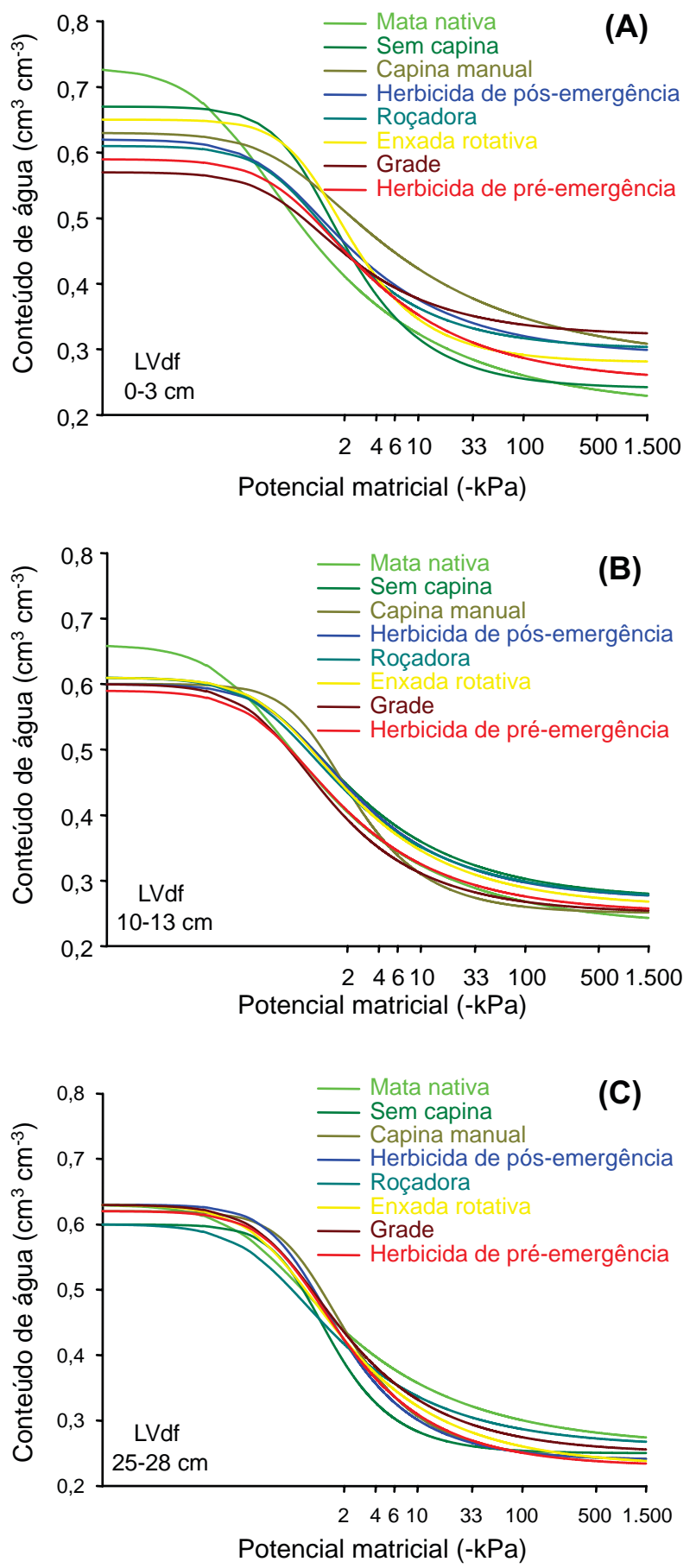

Figura 1 - Curvas de retenção de água para o LVdf sob mata nativa e submetido a diferentes sistemas de manejo de plantas invasoras, nas profundidades de $0-3 \mathrm{~cm}(\mathrm{~A}), 10-13 \mathrm{~cm}$ (B) e $25-28 \mathrm{~cm}(\mathrm{C})$.

potenciais matriciais de $-100 \mathrm{kPa}-1.500 \mathrm{kPa}$, as curvas de retenção de água do LVdf sob MATA e submetido a diferentes manejos de plantas invasoras na profundidade de $0-3 \mathrm{~cm}$ não exibem aspecto próximo ao retilíneo, assintótico ao eixo da abscissa, como observado por Oliveira et al. (2004) em um Latossolo submetido à semeadura direta e ao preparo com arado de discos por 20 anos. Por outro lado, nas profundidades de 10-13 e 25-28 cm, as curvas de retenção de água exibiram comportamento próximo ao retilíneo e assintótico ao eixo da abscissa, corroborando estudo de Oliveira et al. (2004).

Nas profundidades de $10-13$ e $25-28 \mathrm{~cm}$, pequenas alterações foram observadas na distribuição de poros por tamanho (Tabela 3 e Figura 2), o que se refletiu na similaridade das formas das curvas de retenção de água (Figura 1B, C). Portanto, as maiores alterações estruturais promovidas pelo manejo de plantas invasoras ocorrem na superficie, em virtude do contato direto dos equipamentos e do impacto das gotas de chuva.

\section{Distribuição de poros por tamanho}

A distribuição de poros por tamanho foi alterada pela adoção dos diferentes sistemas de manejo de plantas invasoras (Tabela 3). No geral, foram obtidos maiores volumes de poros nas classes $>145 \mu \mathrm{m}$ e $<0,2 \mu \mathrm{m}$ e menores nas classes intermediárias entre 145 e $0,2 \mu \mathrm{m}$ (Tabela 3). Esse aspecto faz com que solos com mineralogia gibbsítica, elevados teores de óxidos totais e estrutura granular, como os do presente estudo, apresentem reduzida disponibilidade de água às plantas (Carducci et al., 2011), apesar do elevado conteúdo de argila. Solos com essas características apresentam predominantemente duas classes de poros distintas: a primeira, relacionada àqueles muito grandes drenados com pequenas reduções; e a segunda, a poros muito pequenos, nos quais a água é retida com energia muito alta, caracterizando-a como água higroscópica (Oliveira et al., 2004; Carducci et al., 2011).

No LVdf sob MATA, o volume de poros $>145 \mu \mathrm{m}$ reduz com o aumento da profundidade, ao passo que o volume de poros $<0,2 \mu \mathrm{m}$ aumenta. O volume de poros $>145 \mu \mathrm{m}$ para o solo cultivado com cafeeiros e submetido a diferentes manejos de plantas invasoras não foi alterado com a profundidade, exceto para o 
Tabela 3 - Distribuição dos poros por tamanho do Latossolo Vermelho distroférrico típico (LVdf) em três profundidades, sob mata nativa e lavoura cafeeira submetida a diferentes sistemas de manejo de plantas invasoras

\begin{tabular}{|c|c|c|c|c|c|c|c|c|c|c|}
\hline \multirow{3}{*}{$\begin{array}{c}\text { Classe de } \\
\text { poro } \\
(\mu \mathrm{m})\end{array}$} & \multicolumn{9}{|c|}{ Uso e manejo de plantas invasoras } & \multirow{3}{*}{$\mathrm{CV}(\%)$} \\
\hline & Profundidade & MATA & SCAP & CAPM & HPOS & ROÇA & ENRT & GRAD & HPRE & \\
\hline & $(\mathrm{cm})$ & \multicolumn{8}{|c|}{$\left(\mathrm{cm}^{3} \mathrm{~cm}^{-3}\right)$} & \\
\hline \multirow{4}{*}{$>145$} & $0-3$ & $0,32 \mathrm{aA}$ & $0,20 \mathrm{aB}$ & $0,13 \mathrm{aB}$ & $0,16 \mathrm{aB}$ & $0,16 \mathrm{aB}$ & $0,17 \mathrm{aB}$ & $0,12 \mathrm{bB}$ & $0,14 \mathrm{bB}$ & \multirow{4}{*}{17,07} \\
\hline & $10-13$ & $0,25 \mathrm{bA}$ & $0,16 \mathrm{aB}$ & $0,16 \mathrm{aB}$ & $0,16 \mathrm{aB}$ & $0,20 \mathrm{aA}$ & $0,16 \mathrm{aB}$ & $0,20 \mathrm{aA}$ & $0,19 \mathrm{aA}$ & \\
\hline & $25-28$ & $0,17 \mathrm{cA}$ & $0,18 \mathrm{aA}$ & $0,17 \mathrm{aA}$ & $0,20 \mathrm{aA}$ & $0,17 \mathrm{aA}$ & $0,21 \mathrm{aA}$ & $0,22 \mathrm{aA}$ & $0,20 \mathrm{aA}$ & \\
\hline & $\mathrm{CV}(\%)$ & \multicolumn{8}{|c|}{17,42} & \\
\hline \multirow{4}{*}{$145-50$} & $0-3$ & $0,12 \mathrm{aA}$ & $0,12 \mathrm{aA}$ & $0,07 \mathrm{aB}$ & $0,07 \mathrm{aB}$ & $0,07 \mathrm{aB}$ & $0,10 \mathrm{aA}$ & $0,04 \mathrm{aB}$ & $0,07 \mathrm{aB}$ & \multirow{4}{*}{32,51} \\
\hline & $10-13$ & $0,09 \mathrm{aA}$ & $0,09 \mathrm{bA}$ & $0,08 \mathrm{aA}$ & $0,07 \mathrm{aA}$ & $0,06 \mathrm{aA}$ & $0,09 \mathrm{aA}$ & $0,06 \mathrm{aA}$ & $0,07 \mathrm{aA}$ & \\
\hline & $25-28$ & $0,11 \mathrm{aA}$ & $0,07 \mathrm{bA}$ & $0,09 \mathrm{aA}$ & $0,09 \mathrm{aA}$ & $0,07 \mathrm{aA}$ & $0,08 \mathrm{aA}$ & $0,07 \mathrm{aA}$ & $0,09 \mathrm{aA}$ & \\
\hline & $\mathrm{CV}(\%)$ & \multicolumn{8}{|c|}{20,45} & \\
\hline \multirow{4}{*}{$50-2,9$} & $0-3$ & $0,04 \mathrm{aB}$ & $0,08 \mathrm{aA}$ & $0,11 \mathrm{aA}$ & $0,08 \mathrm{aA}$ & $0,05 \mathrm{aB}$ & $0,08 \mathrm{aA}$ & $0,07 \mathrm{aA}$ & $0,09 \mathrm{aA}$ & \multirow{4}{*}{25,42} \\
\hline & $10-13$ & $0,04 \mathrm{aA}$ & $0,07 \mathrm{aA}$ & $0,08 \mathrm{aA}$ & $0,08 \mathrm{aA}$ & $0,05 \mathrm{aA}$ & $0,07 \mathrm{aA}$ & $0,07 \mathrm{aA}$ & $0,07 \mathrm{aA}$ & \\
\hline & $25-28$ & $0,05 \mathrm{aA}$ & $0,07 \mathrm{aA}$ & $0,08 \mathrm{aA}$ & $0,08 \mathrm{aA}$ & $0,06 \mathrm{aA}$ & $0,08 \mathrm{aA}$ & $0,07 \mathrm{aA}$ & $0,07 \mathrm{aA}$ & \\
\hline & $\mathrm{CV}(\%)$ & \multicolumn{8}{|c|}{26,75} & \\
\hline \multirow{4}{*}{$2,9-0,2$} & $0-3$ & $0,04 \mathrm{aA}$ & $0,03 \mathrm{aB}$ & $0,04 \mathrm{aA}$ & $0,02 \mathrm{aB}$ & $0,03 \mathrm{aB}$ & $0,02 \mathrm{aB}$ & $0,02 \mathrm{aB}$ & $0,04 \mathrm{aA}$ & \multirow{4}{*}{21,12} \\
\hline & $10-13$ & $0,05 \mathrm{aA}$ & $0,02 \mathrm{aB}$ & $0,03 \mathrm{aB}$ & $0,02 \mathrm{aB}$ & $0,03 \mathrm{aB}$ & $0,03 \mathrm{aB}$ & $0,02 \mathrm{aB}$ & $0,03 \mathrm{bB}$ & \\
\hline & $25-28$ & $0,04 \mathrm{aA}$ & $0,03 \mathrm{aA}$ & $0,03 \mathrm{aA}$ & $0,02 \mathrm{aB}$ & $0,03 \mathrm{aA}$ & $0,03 \mathrm{aA}$ & $0,02 \mathrm{aB}$ & $0,04 \mathrm{aA}$ & \\
\hline & $\mathrm{CV}(\%)$ & \multicolumn{8}{|c|}{22,92} & \\
\hline \multirow{4}{*}{$<0,2$} & $0-3$ & $0,21 \mathrm{bC}$ & $0,24 \mathrm{aB}$ & $0,28 \mathrm{aA}$ & $0,29 \mathrm{aA}$ & $0,30 \mathrm{aA}$ & $0,28 \mathrm{aA}$ & $0,32 \mathrm{aA}$ & $0,25 \mathrm{aB}$ & \multirow{4}{*}{6,72} \\
\hline & $10-13$ & $0,23 \mathrm{bA}$ & $0,27 \mathrm{aA}$ & $0,25 \mathrm{bA}$ & $0,27 \mathrm{aA}$ & $0,27 \mathrm{bA}$ & $0,26 \mathrm{aA}$ & $0,25 \mathrm{bA}$ & $0,25 \mathrm{aA}$ & \\
\hline & $25-28$ & $0,26 \mathrm{aA}$ & $0,25 \mathrm{aA}$ & $0,24 \mathrm{bA}$ & $0,24 \mathrm{bA}$ & $0,26 \mathrm{bA}$ & $0,23 \mathrm{bA}$ & $0,25 \mathrm{bA}$ & $0,23 \mathrm{aA}$ & \\
\hline & $\mathrm{CV}(\%)$ & \multicolumn{8}{|c|}{6,90} & \\
\hline
\end{tabular}

Médias seguidas da mesma letra, maiúscula nas linhas e minúsculas nas colunas, dentro de cada variável, não diferem entre si a $5 \%$ de probabilidade pelo teste de Scott-Knott. MATA: mata nativa; SCAP: sem capina; CAPM: capina manual; HPOS: herbicida de pósemergência; ROÇA: roçadora; ENRT: enxada rotativa; GRAD: grade; HPRE: herbicida de pré-emergência; CV: coeficiente de variação.

solo sob os manejos GRAD e HPRE, os quais reduziram o volume na profundidade de 0-3 $\mathrm{cm}$ em relação às demais (Tabela 3). Quando comparado ao solo sob MATA, o cultivado com cafeeiros reduz o volume de poros $>145 \mu \mathrm{m}$ em todos os sistemas de manejo na profundidade de $0-3 \mathrm{~cm}$, indicando que a ação antrópica ao longo de 30 anos e o uso do solo com cafeeiros podem reduzir inclusive a infiltração de água no perfil do solo, bem como o potencial de recarga do lençol freático. Esse aspecto havia sido destacado por Timm et al. (2005, 2006), os quais observaram que modificações na estrutura de solos cultivados com cafeeiros, mesmo nas entrelinhas, alteram a condutividade hidráulica do solo e as taxas de infiltração de água, durante as chuvas ou irrigações. Solos com menores volumes de poros na superfície reduzem a taxa de infiltração de água no perfil, o que os torna mais propensos à erosão laminar (Pagliai, 2007). Além disso, o controle de plantas invasoras pode alterar a atividade biológica (Faria et al., 1998; Pagliai, 2007) e, portanto, afetar a preservação e a formação dos bioporos (canais formados pelas raízes, minhocas e insetos de solo), importantes para o movimento de água e gases no solo e desenvolvimento radicular.

Na profundidade de $10-13 \mathrm{~cm}$, o volume de poros $>145 \mu \mathrm{m}$ reduz no solo cultivado com cafeeiro sob os manejos SCAP, CAPM, HPOS e ENRT, em relação ao solo sob MATA (Tabela 3). Os sistemas de manejo mecânicos de plantas daninhas ROÇA e GRAD e o químico HPRE não alteraram o volume de poros $>145 \mu \mathrm{m}$ na profundidade de $10-13 \mathrm{~cm}$, quando comparado ao solo sob MATA, indicando que a influência desses manejos ocorre em profundidades inferiores a $10 \mathrm{~cm}$. Esse resultado pode ser atribuído a camadas de maior resistência mecânica na superfície do solo, as quais impedem que as tensões exercidas pelas máquinas e equipamentos aplicados na superficie sejam distribuídas em maiores profundidades (Araujo Junior et al., 2011). Esse efeito pode ser benéfico ao crescimento e desenvolvimento do 

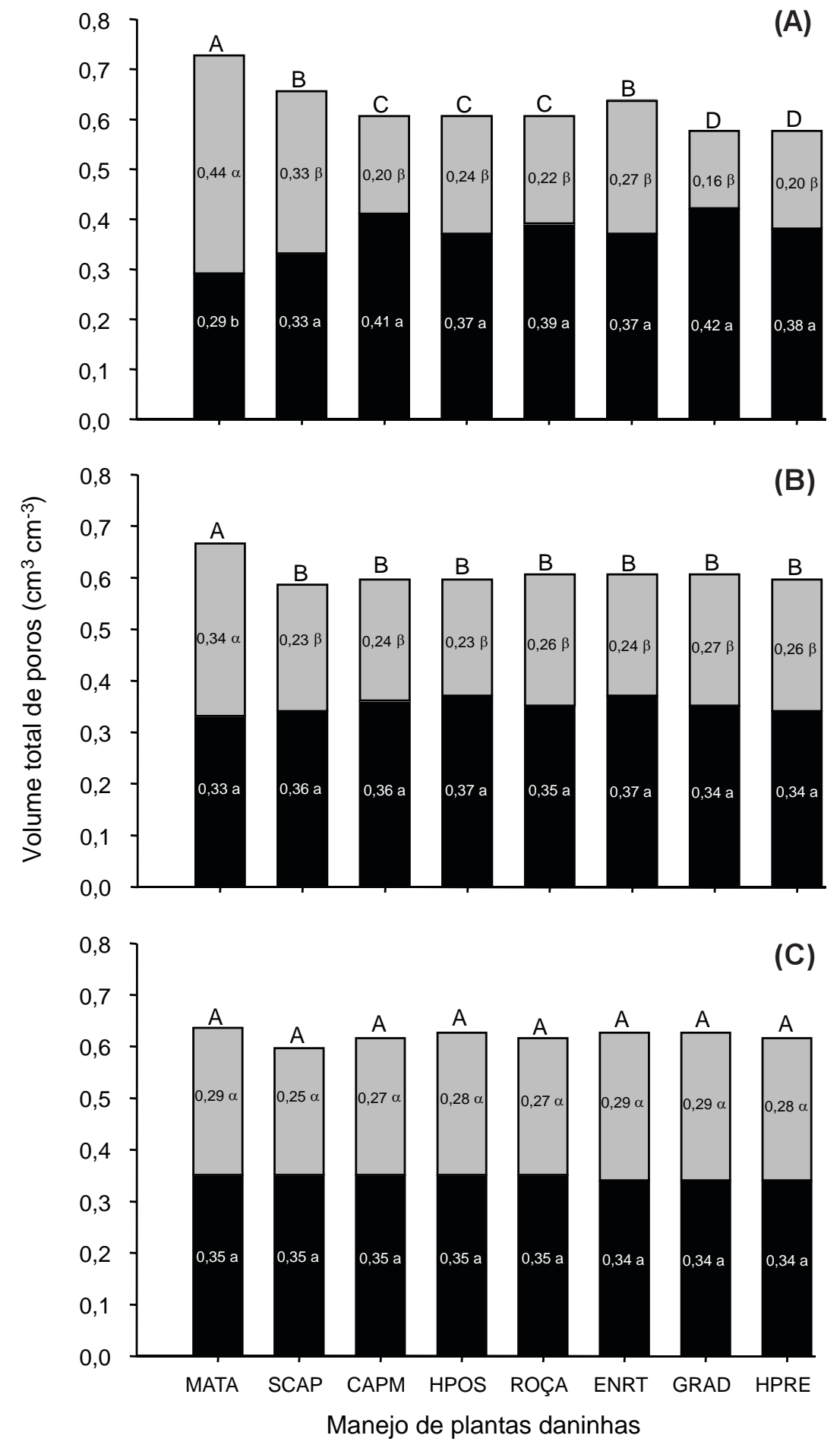

Microporos $(\phi<50 \mu \mathrm{m})$ Macroporos $(\phi>50 \mu \mathrm{m})$

Médias seguidas da mesma letra não diferem entre si (maiúscula-VTP; minúscula - microporos; e grega - macroporos) a 5\% de probabilidade pelo teste de Scott-Knott.

Figura 2 - Volume total de poros, macroporos e microporos de um Latossolo Vermelho distroférrico típico (LVdf), sob mata nativa e lavoura cafeeira submetida a diferentes sistemas de manejo de plantas invasoras, nas profundidades de $0-3 \mathrm{~cm}(\mathrm{~A}), 10-13 \mathrm{~cm}$ (B) e $25-28 \mathrm{~cm}(\mathrm{C})$. 
sistema radicular dos cafeeiros nas entrelinhas em subsuperficie. Esse provável efeito benéfico de um pequeno grau de compactação na camada superficial é semelhante ao observado por Voorhees (1989) na linha de tráfego das máquinas e equipamentos. Esse autor observou que o comprimento radicular total de plantas de milho no perfil do solo foi reduzido pela compactação superficial em sistemas de preparo do solo com arado de aivecas, porém aumentou em áreas com pouco revolvimento do solo, não interferindo no crescimento das raízes em camadas mais profundas.

Na profundidade de $25-28 \mathrm{~cm}$, a classe de poros > $145 \mu \mathrm{m}$ não foi alterada com o uso do solo cultivado com cafeeiros e submetido a diferentes manejos de plantas invasoras, demonstrando que, neste estudo, os efeitos dos sistemas de manejo das plantas invasoras se concentraram nas camadas superficiais.

Os sistemas de manejo CAPM, HPOS, ROÇA, GRAD e HPRE reduziram o volume da classe de poros de $145-50 \mu \mathrm{m}$ na profundidade 0-3 cm, quando comparados aos demais sistemas de manejo das plantas invasoras e do solo sob mata nativa (Tabela 3). Nas profundidades de $10-13$ e $25-28 \mathrm{~cm}$, o uso do solo com cafeeiro e sob diferentes sistemas de manejo não alterou a classe de poros de 145-50 $\mu \mathrm{m}$, em comparação com o solo sob mata nativa.

O uso do solo com MATA reduz o volume de poros da classe de 50-2,9 $\mu \mathrm{m}$ na profundidade de $0-3 \mathrm{~cm}$, em relação ao solo sob cafeeiro e submetido a diferentes sistemas de manejo de plantas invasoras (Tabela 3), o que, provavelmente, está relacionado ao decaimento na capacidade de retenção de água do solo sob mata nativa, com a redução do potencial matricial de $-6 \mathrm{kPa}$ para $-100 \mathrm{kPa}$ (Figura 1A). Nas demais profundidades, não houve efeito dos diferentes sistemas de manejo de plantas invasoras na classe de poros de $50-2,9 \mu \mathrm{m}$ (Tabela 3).

O uso do solo MATA e os manejos SCAP e HPRE proporcionaram ao LVdf, na profundidade de $0-3 \mathrm{~cm}$, menores volumes de poros na classe $<0,2 \mu \mathrm{m}$, em relação ao solo sob os demais manejos de plantas invasoras. Nas demais profundidades, o volume de poro na classe de $<0,2 \mu \mathrm{m}$ não foi alterado pelo uso do solo com cafeeiros nem pelos diferentes manejos de plantas invasoras.
Na Figura 2 estão apresentados os valores médios do volume total de poros, macroporosidade e microporosidade do LVdf sob os usos mata nativa e cafeeiros, submetido a diferentes sistemas de manejo de plantas invasoras, nas profundidades de $0-3,10-13$ e $25-28 \mathrm{~cm}$.

O uso do solo com MATA favorece maior volume total de poros ao LVdf nas profundidades de $0-3 \mathrm{~cm}$ e $10-13 \mathrm{~cm}$, quando comparado ao solo com cafeeiros e submetido a diferentes sistemas de manejo de plantas invasoras (Figura 2A, B). Isso se deve à ausência de ação antrópica, o que proporciona maior estabilidade estrutural, ausência de compactação do solo e, consequentemente, maior ocorrência de poros da classe $>145 \mu \mathrm{m}$ (Tabela 3). Destaca-se, ainda, que os manejos SCAP e ENRT, entre os utilizados na lavoura cafeeira, apresentam maior volume total de poros na profundidade de $0-3 \mathrm{~cm}$ (Figura 2A). Por sua vez, os manejos GRAD e HPRE, na profundidade de $0-3 \mathrm{~cm}$, proporcionaram ao LVdf o menor volume total de poros.

Os manejos de plantas invasoras reduzem o volume de macroporos nas profundidades de 0-3 e 10-13 cm, em relação ao solo sob MATA (Figura 2). O manejo GRAD proporciona valor de macroporos na profundidade de $0-3 \mathrm{~cm}$ (Figura 2) próximo ao considerado crítico $0,15 \mathrm{~cm}^{3} \mathrm{~cm}^{-3}$ (Megda et al., 2008), o que possivelmente compromete o movimento e a transmissão de água e gases no solo. No entanto, o uso do solo com cafeeiros e submetido a diferentes manejos durante três décadas não alterou a macroporosidade a ponto de limitar as trocas gasosas $<0,10 \mathrm{~cm}^{3} \mathrm{~cm}^{-3}$ (Grable, 1971 citado por Stepnieski et al., 1994) ou indicar solo compactado (Pagliai et al., 2004).

Os manejos GRAD e HPRE reduzem o VTP, e os cafeeiros sob estes manejos podem ser prejudicados quanto à produção devido à redução na macroporosidade na profundidade de $0-3 \mathrm{~cm}$. Além disso, esses manejos proporcionaram erosão laminar e perda de água e sedimentos nas entrelinhas dos cafeeiros, tal como foi observado no campo. Segundo Hillel (1970), quanto mais compactado o solo, menor será sua porosidade total e, especialmente, tanto menor será o conjunto de poros existentes entre os agregados. 
O uso do solo com cafeeiros reduziu a porosidade total e a macroporosidade na profundidade de 10-13 cm, em relação ao solo sob mata nativa. Entretanto, não houve qualquer efeito nessas variáveis entre os diferentes manejos de plantas invasoras na profundidade de $10-13 \mathrm{~cm}$. A redução na porosidade total na profundidade de $0-3 \mathrm{~cm}$ do solo sob os manejos GRAD e HPRÉ pode ser considerada outro aspecto nocivo da utilização constante desses manejos. A compactação da camada superficial, além do impacto direto das gotas de chuva (encrostamento superficial), pode ser causada pela tensão cisalhante imposta pelo impacto direto das gotas de chuva e pelas máquinas e implementos em solos continuamente preparados. Em solos constantemente preparados, o cisalhamento provoca a ruptura da continuidade dos poros, reduzindo a condutividade hidráulica do solo saturado, o que resulta em aumento do escoamento superficial e erosão do solo (Pagliai et al., 2004). Portanto, para contornar os impactos diretos e indiretos do manejo de plantas invasoras, uma abordagem holística deve ser adotada, com base no sistema solo-água-planta.

A microporosidade do LVdf aumenta na profundidade de $0-3 \mathrm{~cm}$ no solo cultivado com cafeeiros, em relação àquele sob mata nativa (Figura 2). Esse comportamento pode ser atribuído à história do manejo do solo sob lavoura cafeeira, o que pode transformar parte da macroporosidade em microporosidade. Esse aspecto pode ser considerado benéfico à disponibilidade de água para as plantas nesses solos com menor distribuição de poros intermediários e com baixa capacidade de armazenamento de água (Oliveira et al., 2004). No entanto, nas demais profundidades essa propriedade não foi influenciada pelos diferentes manejos de plantas invasoras na lavoura cafeeira e submetida a diferentes sistemas de manejo (Figura 2). Essa propriedade do solo pode não ser influenciada pelo manejo, como sugerem van den Akker \& Soane (2005).

Não houve efeito dos diferentes sistemas de manejo de plantas invasoras na porosidade total, na macroporosidade e na microporosidade do LVdf em relação ao solo sob MATA, na profundidade de $25-28 \mathrm{~cm}$ (Figura $2 \mathrm{C}$ ), evidenciando que os efeitos do manejo de plantas invasoras na estrutura do solo são restritos às profundidades inferiores a $25 \mathrm{~cm}$, corroborando os resultados obtidos por Araujo Junior et al. (2011). Esses autores destacaram que o conteúdo de carbono orgânico e a densidade do solo também não foram alterados pelos diferentes manejos de plantas invasoras nas entrelinhas dos cafeeiros na profundidade de 25-28 cm. Assim, esses estudos concordam com os resultados de Alcântara \& Ferreira (2000b), os quais destacaram que a maior influência dos manejos de plantas invasoras nas entrelinhas dos cafeeiros em atributos físicos ocorre em profundidades até $15 \mathrm{~cm}$.

Para as condições deste estudo, os diferentes manejos de plantas invasoras utilizados na lavoura cafeeira alteraram o sistema poroso e a capacidade de retenção de água pelo Latossolo Vermelho distroférrico, principalmente na profundidade de $0-3 \mathrm{~cm}$.

A microporosidade do Latossolo Vermelho distroférrico sob lavoura cafeeira aumenta quando comparada à do solo sob mata nativa na profundidade de $0-3 \mathrm{~cm}$, mas não foi alterada nas profundidades de 0-3, 10-13 e 25-28 cm para o solo sob lavoura cafeeira e submetido a diferentes sistemas de manejo.

O uso do solo com cafeeiros reduziu a porosidade total e a macroporosidade nas profundidades de 0-3 e 10-13 cm, em relação ao solo sob mata nativa.

Não houve efeito dos diferentes sistemas de manejo de plantas invasoras na porosidade total, na macroporosidade e na microporosidade na profundidade de $25-28 \mathrm{~cm}$, do LVdf, em relação ao solo sob MATA.

Os manejos grade e herbicida de préemergência foram os que mais reduziram a qualidade da estrutura do Latossolo, na profundidade de $0-3 \mathrm{~cm}$.

\section{LITERATURA CITADA}

AJAYI, A. E. et al. Strength attributes and compaction susceptibility of Brazilian Latosols. Soil Tillage Res., v. 105, n. 1, p. 122-127, 2009.

ALCÂNTARA, E. N.; FERREIRA, M. M. Efeito de diferentes métodos de controle de plantas daninhas sobre a produção de cafeeiros instalados em Latossolo Roxo distrófico. Ci. Agrotecnol., v. 24, n. 1, p. 54-61, 2000 a. 
ALCÂNTARA, E. N.; FERREIRA, M. M. Efeito de métodos de controle de plantas daninhas na cultura do cafeeiro (Coffea arabica L.) sobre a qualidade física do solo. R. Bras. Ci. Solo, v. 24, n. 4, p. 711-721, 2000b

ARAUJO JUNIOR, C. F. et al. Resistência à compactação de um Latossolo cultivado com cafeeiro, sob diferentes sistemas de manejos de plantas invasoras. R. Bras. Ci. Solo, v. 32, n. 1, p. $25-32,2008$

ARAUJO-JUNIOR, C. F. et al. Capacidade de suporte de carga e umidade crítica de um Latossolo induzida por diferentes manejos. R. Bras. Ci. Solo, v. 35, n. 1, p. 115-131, 2011 .

BLAKE, G. R.; HARTGE, K. H. Bulk density. In: KLUTE, A. (Ed.). Methods of soil analysis. 2.ed. Madison, ASA/ SSSA. 1986a. Part 1. p. 363-375.

BLAKE, G. R.; HARTGE, K. H. Partycle density. In: KLUTE, A. (Ed.). Methods of soil analysis. 2.ed. Madison: American Society of Agronomy, 1986b. Part 1. p. 377-382. (ASA. Agronomy Monography, 9).

CARDUCCI, C. E. et al. Modelagem da curva de retenção de água de Latossolos utilizando a equação duplo van Genuchten. R. Bras. Ci. Solo, v. 35, n. 1, p. 77-86, 2011

CARVALHO, R. et al. Erosão hídrica em Latossolo Vermelho sob diversos sistemas de manejo do cafeeiro no sul de Minas Gerais. Ci. Agrotecnol., v. 31, n. 6, p. 1679-1687, 2007.

DANE, J. H.; HOPMANS, J. W. Hanging water column. In: DANE, J. H.; TOPP, G. C. (Ed.). Methods of soil analysis: physical methods. Madison: Soil Science Society of America, 2002. v. 4. p. 680-683.

DAY, P. R. Particle fractionation and particle-size analysis. In BLACK, C. A. (Ed.). Methods of soil analysis. Madison: American Society of Agronomy, 1965. Part 1. p. 545-567.

DOURADO-NETO, D. et al. Soil water retention curve (SWRC). Version 3.0. Piracicaba: 2001. Software.

EMPRESA BRASILEIRA DE PESQUISA AGROPECUÁRIA - EMBRAPA. Centro Nacional de Pesquisas de Solos. Manual de métodos de análises do solo. 2.ed. Brasília: Produção de Informação, 1997. 212 p.

EMPRESA BRASILEIRA DE PESQUISA AGROPECUÁRIA - EMBRAPA. Centro Nacional de Pesquisas de Solos. Sistema brasileiro de classificação de solos. 2.ed. Rio de Janeiro: Embrapa Solos, 2006. 306 p.

FARIA, J. C. et al. Effects of weed control on physical and micropedological properties of Brazilian ultisol. R. Bras. Ci. Solo, v. 22, n. 3, p. 731-741, 1998.
FERREIRA, D. F. Análises estatísticas por meio do SISVAR para Windows 4. 0. In: REUNIÃO ANUAL DA REGIÃO BRASILEIRA DA SOCIEDADE INTERNACIONAL DE BIOMETRIA, 45., 2000, São Carlos. Anais... São Carlos: Universidade Federal de São Carlos, 2000. p. 255-258.

FERREIRA, M. M.; FERNANDES, B.; CURI, N. Influência da mineralogia da fração argila nas propriedades físicas de Latossolos da região sudeste do Brasil. R. Bras. Ci. Solo, v. 23 , n. 3 , p. $515-524,1999$

FLINT, L. E.; FLINT, A. Porosity. In: DANE, J. H.; TOPP, G. C. (Eds.). Methods of soil analysis: physical methods. Madison: Soil Science Society of America, 2002. v. 4. p. 680683 .

GROHMANN, F.; RAIJ, B. van. Dispersão mecânica e pré-tratamento para análise granulométrica de Latossolos argilosos. R. Bras. Ci. Solo, v. 1, n. 1, p. 52-53, 1977.

GROSSMAN, R. B.; REINSCH, T. G. Bulk density and linear extensibility. In: DANE, J. H.; TOPP, G. C. (Eds.) Methods of soil analysis: physical methods. Madison: Soil Science Society of America, 2002. v. 4. p. 201-228.

GLIÑSKI, J.; LIPIEC, J. Soil physical conditions and plant roots. Boca Raton: CRC Press, 1990.

HILLEL, D. Solo e água: fenômenos e princípios físicos. Traduzido pelo convênio UFRGS-USAID/Winconsin. Publicado pelo Departamento de Solo-UFRGS. Porto Alegre 1970. $231 \mathrm{p}$.

HORTON, R.; THOMPSON, M. L; McBRIDE, J. F. Method of estimating the travel time of noninteracting solutes through compacted soil material. Soil Sci. Soc. Am. J., v. 51, p. 48-53, 1987.

HORTON, R.; ALLMARAS, R. R.; CRUSE, R. M. Tillage and compactive effects on soil hydraulic properties and water flow. In: LARSON, W. E. et al. (Eds.). Mechanics and related processes in structured agricultural soils Dordrecht: Kluwer Academic Publishers, 1989. p. 173-186.

KLUTE, A. Water retention: laboratory methods. In: KLUTE, A. (Ed.). Methods of soil analysis: physical and mineralogical methods. Madison, American Soil Society of Agronomy, 1986. v. 1. p. 635-660.

KUTILEK, M.; NIELSEN, D.; REICHARDT, K. Soil water retention curve, interpretation. Trieste: Lecture Notes College on Soil Physics, International Centre for Theoretical Physics, 2007.

MEGDA, M. M. et al. Correlação linear e espacial entre a produtividade de feijão e a porosidade de um Latossolo Vermelho de Selvírica (MS). R. Bras. Ci. Solo, v. 32, n. 2, p. 781-788, 2008. 
OLIVEIRA, G. C. et al. Caracterização química e físicohídrica de um Latossolo Vermelho após vinte anos de manejo e cultivo do solo. R. Bras. Ci. Solo, v. 38, n. 2, p. 327-336, 2004.

PAGLIAI, M. Soil structure. Trieste: College on Soil Physics, International. Centre for Theoretical Physics, 2007. 27 p. Lecture Notes.

PAGLIAI, M.; VIGNOZZI, N.; PELLEGRINI, S. Soil structure and the effect of management practices. Soil Tillage Res., v. 79, p. 131-143, 2004.

PAGLIAI, M. et al. Tillage impact on soil quality. I. Soil porosity and related physical properties. Italian J. Agron., v. 2, n. 1, p. 11-20, 1998.

PIRES, L. F. et al. Soil porous system changes quantified by analyzing soil water retention curve modifications. Soil Tillage Res., v. 100, p. 72-77, 2008.

RESENDE, M.; SANTANA, D. P. Uso das relações Ki e Kr na estimativa da mineralogia para classificação de Latossolos. In: REUNIÃO DE CLASSIFICAÇÃO, CORRELAÇÃO DE SOLOS E INTERPRETAÇÃO DA APTIDÃO AGRÍCOLA, 3., 1988, Rio de Janeiro. Anais... Rio de Janeiro: EMBRAPA/ SNLCS/SBCS, 1988. p. 225-232.

RODRIGUES, B. N.; ALMEIDA, F. S. Guia de herbicidas 5.ed. Londrina: IAPAR, 2005. 592 p.

RONCHI, C. P.; SILVA, A. A. Effects of weed species competition on the growth of young coffee plants.

Planta Daninha, v. 24, n. 3, p. 415-423, 2006.
TIMM, L. C. et al. Soil bulk density evaluation by conventional and nuclear methods. Austr. J. Soil Res., v. 43, p. 97-103, 2005

TIMM, L. C. et al. Field spatial and temporal patterns of soil water content and bulk density changes. Sci. Agric., v. 63, n. 1, p. 55-64, 2006

TOPP, G. C.; FERRÉ, P. A. Water content. In: DANE, J. H.; TOPP, G. C. (Eds.). Methods of soil analysis: physical methods. Madison: Soil Science Society of America, 2002. v. 4. p. $417-424$.

STEPNIEWSKI, W.; GLIÑSKI, J.; BALL, B. C. Effects of compaction on soil aeration properties. In: SOANE, B. D.; OUWERKERK, C. van. (Eds.). Soil compaction in crop production. Amsterdam: Elsevier, 1994. p. 45-69.

van den AKKER, J. J. H.; SOANE, B. Compaction. In: HILLEL, D. et al. Encyclopedia of soils in the environment. New York: Academic, 2005. v. 1. p. 285-293.

van GENUCHTEN, M. T. H. A closed-form equation for predicting the hydraulic conductivity of unsaturated soil. Soil Sci. Soc. Am. J., v. 44, p. 892-898, 1980.

VOMOCIL, J. A. Porosity. In: BLAKE, C. A. Methods of soil analysis. Madison: American Society of Agronomy, 1965.

VOORHEES, W. B. Root activity related to shallow and deep compaction. In: LARSON, W. E. et al. (Eds.). Mechanics and related processes in structured agricultural soils. Dordrecht: Kluwer Academic, 1989. p. 173-186. 